\title{
Manifestation of digital transformation risks - marginality or insight?
}

\author{
E.V. Pavlova, A.N. Sunami \\ Department of Conflictology, St. Petersburg State University, St. Petersburg, Russia
}

\begin{abstract}
Today the conflict nature of digital transformation became apparent. However, very limited study has been carried out on this issue. The aim of this study is today a theoretical basis for further studies. The authors systematize theoretical and practical material and made a critical selection of relevant conceptual tools focused on analyzing the interrelation of risk-reflections and conflict management strategies. Using riskreflective and conflict logical approaches, the authors came to the conclusion that digital transformation can be perceived by social actors as a risk, and as a reflection of this reaction, may ignite social conflicts. It was inferred that the destructive risk reflection can be presented as an unrealistic conflict, in which real object is replaced by a false one and demonstrates an inadequate choice of response to threats and risks. Thus, the development of tools for such reflections and interventions allows transforming the response to threats towards strengthening the constructive component, therefore preventing violent unrealistic conflicts owing to risks.
\end{abstract}

\section{Introduction}

The relevance of the research topic is defined by both the active spreading of digital technologies in all spheres of life of modern society and the changes that these technologies bring to everyday life. The current digital era permeates our lives so much that modern technology not only defines society but also in many ways creates a society where risks and conflicts take place. Digital transformation is the result of a number of socio-economic and technological developments. This transformation process makes certain adjustments to the social structure, essentially transforming it. The era of digital technologists is characterized by ambiguity and duality: on the one hand, a huge number of opportunities and certain freedom opens up for a person, and on the other, new forms and types of dependencies, risks, and conflicts appear [1]. This transformation is most noticeable in the oil and gas industry, where digitalization is seen as the main way to increase the competitiveness and profitability of the business. The scientific novelty of the research is determined by the fact that while experts in the mining industry have noted that the benefits of digital technology have some risks, e.g., low network bandwidth, lack of necessary qualification, organizational barriers, cyber security issues in the country, financial constraints, there are also certain risks of conflicts. Based on the idea of the similarity between risks and conflicts, we can say that the conflict activity of individuals manifests itself as a reaction to the risks actualized for them. According to A. Giddens, "risk is a dynamic mobilizing force 
in a society striving for change, wishing to independently determine its future, and not leave it at the mercy of religion, traditions or the vagaries of nature" [2].Thus, many individuals, in response to the threat of digital transformation, in an attempt to change the situation and confront those who disagree with it, produce conflicts. As a part of the means of adapting to risks and protecting against dangers, people begin to exhibit deviant behavior. A pronounced intolerance, even hostile attitude towards those who are attributed to risk sources and blamed for changes in the usual way of life, as well as division into "friends" and "foes" appear. So, who are those who are against digital transformation? Are they marginalized or visionary? Anyway, there is no doubt that the use of digital technologies, such as artificial intelligence, puts enormous pressure on workers because of changing work standards and efficiency, and therefore, they increase stress and anxiety, which leads to a deterioration in both physical and mental health and jeopardizes safety in the workplace [3].

Despite the rich international experience of studying risks and the popularity of discourse methods of social analysis, most of these areas and models continue to be quite significant. Recently, many researchers noted that classical concepts are no longer enough to explain the perception of modern risks by social actors [4]. It is for these reasons that the concept of the uncertainty of the consequences of risk perception has become central to the risk studies in various disciplines [5]. The main elements of risk in the modern literature include the results that affect what people value, the probability of occurrence (uncertainty), and the specific context in which risk may arise [6]. Thus, social sciences today focus on the socio-cultural and political context, recognizing that risk and the problems associated with it are deeply rooted in the societies in which they arise. Sociological studies include many different theoretical and empirical approaches, which in recent years have been the subject of various attempts to conceptualize risk-reflections [7]. Such a variety of modern points of view shows that the overall task of accurate sociological determination of risks and risk-reflections has not been achieved. On the contrary, it was observed that an ambivalent epistemological understanding of risk leads to inconsistent use of the term [8].

\section{Materials and methods}

For the purposes of the research, it is necessary to synthesize all general theoretical and applied research programs, among which the classical works of Beck U., Giddens E., Douglas M., Durkheim E., Luhmann N., Merton R., Mikhailovsky N.K., Knight F., Sorokina P.M., and many others. The list of relevant Russian contemporaries includes Algin A.P., Mozgovaya A.V., Kornilov T.V., Yanitsky O.N., Yakovenko I.G., PlotinskyYu.M.,Prigozhin A.I., Podkolzin I.A., Avtonomov A.C., Sillaste G.G., and other profound authors. Since bibliographic reviews of risk-related problems are rather complete in the modern literature, we will identify only several areas that seem to have the best heuristic potential for our research.

At the outset, it should be recognized that a conflictual interpretation of risk is certainly productive. Beck W. considers the arrangement of political forces as a conflict and a struggle for the opportunity to define "what is risky and what is not." This concept emphasizes the distribution of risks in society and the contradictions between those who are exposed to risks and those who benefit from them; those who create risks, and those who take them. Beck's theory refers to the relationship between the dynamics of a political conflict and the interpretation of risks as "hidden demons" when they are strategically defined, disguised, or inflated.

From the standpoint of conflict management, every risk model should take into consideration the authentic works by Marx K. (inequality of economic status) and Dahrendorf R. (inequality of authority positions), Durkheim E., Parsons T. and Merton R. 
(structural-functional theory), Simmel G. and CoserL. (concepts of positive-functional conflict), Galtung I. (structural violence), Boulding K. (general theory of conflict), Kriesberg L. (analytical model of conflict as a system of structural and dynamic indicators), McKay R. and Snyder R. (generalized model of conflict and conflict identification), Burton J. (conflict resolution based on the identification of infringed human needs), Tilly Ch. (theory of collective action), Deutsch M. (game-theoretical model of conflict), Rex D. (model of the conflict society).

Special attention should be paid to the general theory of conflict by Boulding K. and Kriesberg L., in which the basic analytical options include the structural parameters of conflicts: static (object, subject, subjects of conflict, a zone of disagreements, etc.) and dynamic (the definition of the current stage of conflict deployment) factors that affect the escalation or de-escalation of conflicts. Searching for other factors that influence conflicts, most researchers focus on the problems of inequality and political instability, the impact of ethnic differences on social-political conflicts, the demographic factor in the development of social contradictions.

To understand the concept of digital transformation as a profound transformation of the economic, political, social, and spiritual spheres of society through the integration of digital technologies into the processes of human life and activity, a process leading to changes in human consciousness and culture, i.e., lifestyle, values, social norms, and even language, which can be of a conflict-generating nature, we must focus on the studies of Vogelsang M. and Bounfour A., as well as on the research program of a scientific group consisting of Collin J., Hiekkanen K., Korhonen J.J., Halén M., Itälä T., Helenius M.

Perelet R.A. mentioned that digital technologies play a crucial role in achieving a longterm balance between the techno sphere and the natural environment, which is necessary for sustainable development. Sustainable development is largely related to the preservation of the biosphere and natural capital together with the techno sphere and sociosphere. However, in real life, environmental aspects are often overlooked. This leads to environmental problems and multiplies the risks for the environment. Therefore, it is necessary to integrate the issues of the impact of the digital economy on the environment. Simplification of environmental impact research breeds unsuccessful technology futures. The digital economy is changing human relationships with the environment. As a solution to environmental problems, for the benefit of the economy, environment, and society, the concept of a "sustainable digital economy" should be implemented [9].

Another important research field represents Durkheim's study of anomalous risks and risks of "inflated expectations"; Luhmann's texts devoted to communicative and noncommunicative risks, the role and functions of "political breeders" in presenting the reality of risks and dangers; and forms of self-modifying leadership that substitutes the threat of "excessive power" with the risk of "insufficient power".

The relevance of Giddens's approach is determined by the fact that he substantiated the link between trust and risk, drew attention to the indeterminism of social structures and the unpredictability of social agents, highlighting the external and man-made risks associated with the correlation of person's awareness and the semantic field of everyday life.

One of the most important content factors that structure the problematic field of the research is the key theoretical and methodological plots by Wildavsky and Dake K., who examine the specific features of risk-taking by different social groups and depending on the entrenched socio-cultural values.

To clarify the theoretical contexts of risk reflection, Kahneman D. proposes a gain-loss analysis that adds value of strategies around "risk in action" and "risk in thinking". The concepts of "unpredictability" and "anti bribery" by Taleb N.as well as tolerance and intolerance to risk and uncertainty by Kornilov TV.are also thematically close to this approach. 
The interpretation of the risk by Douglas M., who justified the political design as "a stick for beating those who have authority" should be also recognized as unconditionally productive. A debate about risk is always a debate about politics and, at the same time, an important integral function of maintaining social solidarity. A special feature of the analytical approach by Draper E. is the inclusion of the term "legitimacy" in the risk study. Risk is a marker of the attitude to the power that determines the justification for its existence.

The focus of our research is largely determined by such classical conceptual systems as Marx's alienation, Weber's typology of social action, Fromm's existential dichotomies, and Merton's forms of adaptation to the goals and institutional means.

From the latest relevant scientific literature, it is worth mentioning the four-volume edition of "Risk" published in 2017 and edited by Burgess A. (University of Kent), which includes several significant articles on the problem of the "risk society" (published in such field-specific journals as Risk Analysis, Journal of Risk Research and Health, Risk and Society).

In addition to the indicated diverse theoretical constructions, considerable experience on the problems of the research has been accumulated within the sociological perception of fears and threats, attitudes toward "The Other," etc. Working on the research, we refer both to the compiled empirical data of Russian (the Institute of Sociology of the Russian Academy of Sciences, VCIOM, FOM, etc.) and foreign studies (the European Social Research (ESS), and the World Values Research (WVS)). Though The studies of risks, discourse strategies, and conflict management is a commonplace for contemporary science, the mixture of all these fields with the same optics has not yet become a notable direction for socio-humanitarian research. In this case, the search for universal mechanisms of riskreflection and the development of discursive strategies in the projection of everyday practices within conflict interactions actualized in the face of risks and threats of different nature make this research paramount and give certain competitive advantages in the application in practice.

\section{Results}

The scientific result of the research will be a conceptual and methodological tool for studying the processes of institutionalizing risk-reflections, the specifics of the Russian model of attitudes to risk, and discourse strategies as ways to structure the risks of social reality in social thinking.

The main research tasks are to find answers to the following questions: what is the direction of the development of the risk-reflexive influence, rooted in the mass consciousness of people, aimed at finding adequate responses to essential challenges to the development of the country? Can the formation of a rational risk-reflexive response to the challenges of normalizing the understanding of the ideal of security and stability, reduce the severity of the false choice between the options of stability and equilibrium and the mechanisms of "creative destruction"?

This scientific result is the basis for the preparation of practical recommendations for the development of a toolkit to diagnose communication strategies of Russian citizens' responses to risks and threats, as well as measures to strengthen the constructive and devaluative impact of risk reflection in conflict management in modern Russia.

As the result of this research, we can define the following outcomes:

First,the development of a new conceptual scheme for studying the place and role of risk-reflection in the formation of adequate and inadequate responses to risks and threats

Second, the discovery of the most significant for the discursive strategies "response to the challenges" of risk reflection, rooted in the modern Russian consciousness 
Third, identification of the essential features, patterns, and mechanisms of discursive orders of modern risks in the projection of communicative spaces of conflict management as an element of forming strategies of preparation for unpredictable situations, resistance to uncertainty, and the concept of socially acceptable risk

Fourth, the formation of a methodology and development of tools for conducting empirical study of constructive and destructive discursive elements of risk-reflection reproduced in daily practice of conflict interactions, mechanisms of public resistance to destabilizing negative risk factors.

Now let's look at the conflict around digital transformation itself. The active introduction of digital technologies is causing fierce debates among politicians, economists, and ordinary people about the impact of this process on society. As digitalization becomes embedded in society, there is growing concern about how it will affect jobs, wages, inequalities, health care, resource efficiency, and safety.

All these people are undoubtedly aware of both the risks and the conflict genetic aspects of this phenomenon. However, despite some common understanding of difficulties, people perceive and evaluate those differently, which leads to the formation of an irreconcilable contradiction between them. And therefore, two sides can be distinguished in this conflict: one includes those who are optimistic and positive about digital transformation and are ready for the changes that it will bring. And the second comprises those who are pessimistic and extremely negative and are afraid of any changes. The object of this conflict is digital transformation. The subject is a different attitude towards digital transformation and its consequences.

One side of the conflict believes that digital transformation is the progress we need and that the changes it will bring will only be for the benefit of society. The second, however, perceive this kind of transformation as destructive progress, believing that it reduces personal privacy, reduces the level of professionalism and competence, and makes people face difficulties in distinguishing between personal and professional life. Among the second group, some call everything "devilish tricks" that will destroy humanity, and perceive any digital changes as another step towards chipization, namely, the introduction of a system of total electronic control over the population.

It is due to such an obvious clash of ardent fans of digitalization and categorical opponents that this confrontation can be viewed as a conflict.

Moreover, we can say that this conflict is asymmetric. On the one hand, the state acts, both in the person of the president and the state apparatus and ministries that are actively introducing digitalization in the spheres of life and activities of the population. Also, many eminent scientists, various educational institutions, and, of course, economic actors are in favor of digital transformation. The position of this side is clearly formulated and reasoned based on various kinds of research. While on the other hand, we can observe some mental instability and marginality of the participants in this conflict: after all, only the church and parishioners, anti-inoculants, and some subjects who are fond of conspiracy theories oppose digital transformation. But, here, it is worth making a reservation, because it is precisely because of the articulation of ideas in such a specific form that an imprint is left on the entire presentation of the negative consequences of digitalization, and real arguments turn out to be inaudible. The second side began to manifest itself most actively in connection with the COVID-19 pandemic around the world; in April 2020, due to the idea of the spread of coronavirus through digital networks, they even began to massively set fire to $5 \mathrm{G}$ towers. The Prosecutor General's Office of the Russian Federation even had to block a huge number of videos claiming that the coronavirus is a genetically modified biological weapon created to to chip the population and establish a new world order. And this is not the first example of such a radical confrontation between those who support the introduction of digital technologies and those who are against it. 
According to the results of an all-Russian study conducted in May 2019 by the NAFI Analytical Center in conjunction with the Digital Economy organization, more than a third of the population fears the introduction of digital technologies. Thus, $37 \%$ of citizens of the Russian Federation feel anxiety when faced with modern technologies, 38\% are anxious about the introduction of technologies into everyday life, $30 \%$ believe that technologies will not bring new knowledge and opportunities, and 35\% believe that the development of digital technologies and their implementation are dangerous in the long term. Thus, we can say that about a third of the citizens of the Russian Federation do not support digital transformation. But there are also those who are optimistic about this kind of change. Thus, $60 \%$ of Russians believe that the development of digital technologies will contribute to solving many modern problems, and $74 \%$ say that innovations will make life easier and more convenient.

It is noteworthy that the positive consequences of the introduction of digital technologies are mentioned by young people aged 18 to 24 , as well as people with higher education, regular work, and high income.

While negative effects are indicated by people over 60 , the unemployed, rural residents, and people with low income.

And this proves our hypothesis that educated and influential people belong to one side of the conflict, and those who are marginal and distrustful with their statements belong to the other.

Moreover, if we proceed from the idea of the similarity of risk and conflict, then we can say that the conflict activity of individuals manifests itself as a response to the actualized risks for them. According to Giddens E., "risk is a dynamic mobilizing force in a society striving for change, willing to independently determine its future, and not to leave it at the mercy of religion, traditions or the whims of nature." Thus, many individuals, in response to the threat of digital transformation, in an attempt to change the situation and confront those who disagree with it, produce conflicts.

As part of the means of adapting to risks and protecting against dangers, citizens begin to exhibit deviant behavior, examples of which are described above. There is a pronounced intolerance, one might even say, hostile attitude towards those who are attributed to sources of risk and are blamed for changes in the habitual way of life, as well as towards those who are "alien" and not "ours".

Thus, the conflict activity of citizens can manifest itself as a response to the actualized risks for them. And as we showed at the beginning of this work, there are a lot of conflict genetic aspects and risks of digital transformation. That is why the emerging conflict between those who support the introduction of digital technologies and those who are against is so intense.

During the study, it was also noticed that the advent of an unrealistic component based on emotions and stereotypes increases conflict. An exaggeration or the understatement of the threat and the substitution of an object of the conflict leads to the prevalence of a destructive risk-reflection. Moreover, it has been found that one of the ways of managing the conflict is to make the response to threats adequate.

\section{Discussion}

The conflict approach allows examining the conflict with regard to digitalization. Furthermore,

it makes it possible to identify the needs and interests of the parties, to determine the degree of their organization and the scope of support. On the other hand, the risk theory allows us to study the existing risk-reflection on digitalization, as it is manifested in the 
minds of people. As we can see, this conflict is generally not recognized as legitimate currently and is asymmetrical.

Since the dominant approaches in modern science tend to develop the problem of riskreflectivity outside the context of the conflict behavior of the object of risk, they miss the point that:

- Any risk is inherently conflicting, because every problem, be it environmental or a threat to cultural identity, can be identified with someone's interests;

- The influence of risk-reflection on adaptation to changing conditions is ambivalent;

- Risk-reflection as a special discursive practice has a high manipulative potential for forming an agenda, choosing a way to protect from threats, and personifying the subject of risk [10].

A fundamentally new moment is the concept of "risk asymmetry" developed by the authors in the conflict logical paradigm, a phenomenon whose intentional base is the dominant role of "asymmetric responses" to challenges and threats. With such an abrupt change in the forces balance in the conflict, the risk becomes non-communicative, associated only with decisions and actions of the authorities (their impulsiveness, distortion of management information, the lack of alternative solutions, the atmosphere of "extreme legitimacy"). The conflict potential of the power and society's orthogonality in the risky space can threaten the norms and values of society.

In the proposed research, risk-reflection is considered as a special type of discursive practices, for which a high degree of manipulation is characteristic, and, therefore, one of the research tasks was to identify mechanisms and parameters for structuring the space of "postponed instability". According to the research team, a special study devoted to the holistic picture of this phenomenon has not yet been conducted.

Using this conceptual approach will allow to:

- Explain how risk-reflection in different conditions can act as a constructive and destructive one;

- Determine the causes and presence of the destructive influence of risk-reflection on discursive strategies of conflict management;

- Forecast the strengthening of constructive/destructive influence of risk-reflection in Russian society.

To avoid social conflicts due to digital transformation risks, it is necessary to carry out a theoretical and empirical analysis of the impact of risk in different social and cultural conditions on the dynamic and structural indicators of the conflict and its management (forecasting, prevention, stimulation, mitigation, settlement, and resolution). Also, universal mechanisms of risk-reflection and the development of discursive strategies in the projection of everyday practices within conflict interactions actualized in the face of risks and threats of different nature should be found. Moreover, it is necessary to identify the role of risks in the emergence of conflict moods in society, to identify realistic and unrealistic risks, the prerequisites for escalating conflicts, and to identify the main interests regulating social relations in conditions of uncertainty. Finally, it is necessary to analyze the social interactions of stakeholders to achieve an acceptable level of risk, to identify the microstructures of social relations that determine the conflict of interests in a risk situation and the choice of risk communication norms, which is an important factor for managerial impact on the conflict. Without the strategic management of conflicts as a complex system of interactions at various levels, it is impossible to identify risks and rank and assess their strength. 


\section{Conclusion}

Methodological guidelines presented in this research allow not so much to identify risks but to develop a mechanism for identifying destructive components in responses to threats and risks in order to change from unrealistic and false conflict to the manifestation of real interests and frustrations of the parties.

The use of the conflict approach and the up-to-date risk explication methodologies allowed the authors to conclude that destructive risk reflection can be presented as a version of a displaced, unrealistic or distributive conflict, in which the real object of contradiction is replaced by a false one, variables of violence and intensity demonstrate an inadequate choice of response to threats and risks, and the unrealistic component based on stereotypes and myths takes precedence over the rational component. Thus, the development of tools for identifying this kind of risk reflection and intervention into it by analogy with a displaced conflict allows us to transform the response to threats in the direction of strengthening the constructive component and thereby preventing violent unrealistic conflicts over risks, including risks in the information sector.

In this research, the main goals were achieved: the theoretical framework for further research was constructed; the theoretical and practical material was systematized, and a critical selection of relevant conceptual tools was made; a set of the most effective approaches and theories that can be used for further research was created; an original conceptual and methodological toolkit for the study of the institutionalization of risk reflections was formed. Nevertheless, a broad discussion is necessary, since the absence of discussion leads to the radicalization of the conflict. It must be admitted that the answer to the question posed in the title can only be answered by examining the conflicting positions of the parties, an assessment of their needs and interests, and their realistic actions. In the meantime, the opposing side is not yet present in social discourse at all.

This work was supported by grant no. 19-18-00115funded by the Russian Science Foundation.

\section{References}

1. M.O. Orlov The conflict potential of social communication in the digital age. Vestnik Sankt-Peterburgskogo Universiteta, Filosofiia I Konfliktologiia 35(3), 485-496 (2019)

2. A. Giddens Runaway World: How Globalization Is Reshaping our Lives,40,(New York: Routledge,2000)

3. N.Stacey, P.Ellwood, S.Bradbrook, J.Reynolds, H.Williams, D. Lye Foresight on new andemerging occupational safety and health risks associated with digitalisation by 2025,(Luxembourg: Publications Office of the European Union, 2018)

4. F.Battistelli, M.G. Galantino Dangers, risks, and threats: An alternative conceptualization for the catch-all concept of risk. Current Sociology, 64-78(2018)

5. T.Aven, S.Guikema On the concept and definition of terrorism risk.Risk Analysis, 35(12), 2162-2171(2015)

6. O. Renn Concepts of risk: An interdisciplinary review. Part 1.Disciplinary risk concepts.GAIA.Ecological Perspectives for Science and Society,17(1), 50-66(2008)

7. U. BeckPioneer in Cosmopolitan Sociology and Risk Society, 78-89(Munich: Springer, 2014) 
8. J.O. Zinn Risk as discourse: Interdisciplinary perspectives. Critical Approaches to Discourse Analysis across Disciplines,4(2), 106-124 (2010)

9. R. A. Perelet Environmental issues in a digital economy. Mirnovojekonomiki (World of thenew economy), 12(4), 39-45 (2018)

10. A.N.Sunami, K.V. Kryukova Conflict studies of modern terrorism in the context of a risk-reflection approach. Vestnik Sankt-Peterburgskogo Universiteta, Filosofiia I Konfliktologiia,36(1), 116-130 (2020) 